\title{
Chylothorax complicating repair of a left diaphragmatic hernia in a neonate
}

\author{
A CZERNIAK, Z DREZNIK, Y NEUMAN, I WOLFSTEIN
}

From the Department of Pediatric Surgery, and Pediatric Intensive Care Unit, Chaim Sheba Medical Center, Sackler Medical School, Tel-Aviv University, Israel

We describe here a case of chylothorax complicating repair of a left posterolateral diaphragmatic hernia. Successful treatment consisted of continuous drainage of the pleural cavity, combined with parenteral hyperalimentation.

\section{Case report}

A $2500 \mathrm{~g}$ term female baby developed severe respiratory distress shortly after birth. A chest radiograph established the diagnosis of a left diaphragmatic hernia (fig 1). She

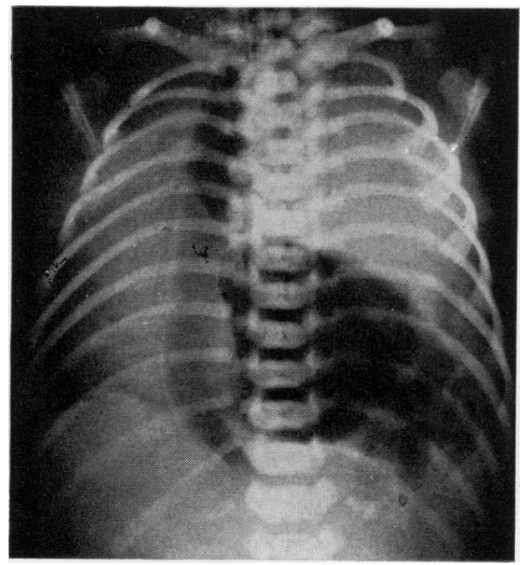

Fig 1 Chest radiograph showing a left diaphragmatic hernia with marked mediastinal shift to right.

was operated on at 6 hours of age through a mid-line abdominal approach when a left posterolateral diaphragmatic defect, measuring 6 by $8 \mathrm{~cm}$ was found. After reduction of the viscera, a small contracted lung was seen, covered by a thin membranous sac. The sac was excised, a left intercostal drain inserted, and the defect closed with interrupted silk sutures. No anomalies of the gastrointestinal tract were noted, and the abdomen was closed without any difficulty.

The child was placed on a volume-controlled respirator

Address for reprint requests: Dr A Czerniak, Ch Sheba Medical Center, Tel-Hashomer, Israel. and there was satisfactory expansion of the left lung. The chest drain was removed on the fourth day. On the seventh day the child's condition deteriorated-with $\mathrm{FiO}_{2} 30 \%, \mathrm{Po}_{2}$ dropped to $50 \mathrm{mmHg}$, and $\mathrm{PCO}_{2}$ increased to $65 \mathrm{mmHg}$. The chest radiograph demonstrated a left pleural effusion and infiltration, and there was an air bronchogram in the right lung. Left thoracocentesis yielded initially $50 \mathrm{ml}$ of clear xanthomatous fluid, and Pseudomonas aeroginosa was found both in the fluid and in the endotracheal suction cultures. Tobramycin and carbenicillin were given for two weeks. Within a few days the child's condition improved, the pleural effusion disappeared, and oral feeding was started.

On the twelfth day, a left pleural effusion was noted (fig 2). A left pleural intercostal drain yielded a creamy

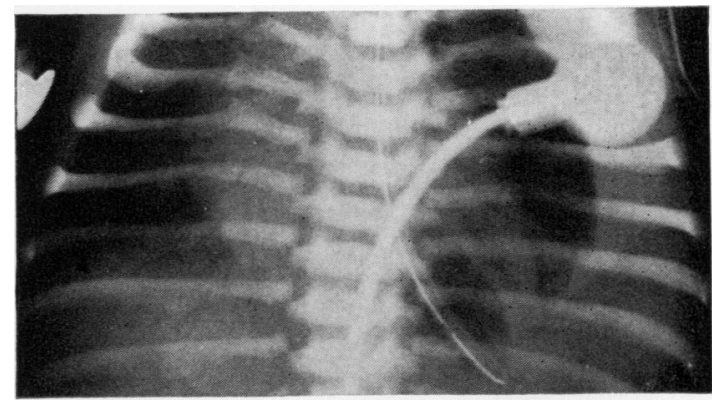

Fig 2 Radiograph taken 12 days after operation shows pleural fluid in left hemithorax.

white fluid, containing, on chemical analysis $0.8 \mathrm{~g}$ per cent $(8.0 \mathrm{~g} / \mathrm{l})$ albumin, $0.5 \mathrm{~g}$ per cent $(5.0 \mathrm{~g} / \mathrm{l})$ globulin, $360 \mathrm{mg}$ per cent $(9.25 \mathrm{mmol} / \mathrm{l})$ cholesterol, and $570 \mathrm{mg}$ per cent $(5.25 \mathrm{mmol} / \mathrm{l})$ triglycerides. Plasma albumin was $2.8 \mathrm{~g}$ per cent $(28 \mathrm{~g} / \mathrm{l})$ and globulin $1.6 \mathrm{~g}$ per cent $(16 \mathrm{~g} / \mathrm{l})$. The lymphocyte count of the fluid was 2675 per $\mathrm{mm}^{3}(2 \cdot 7 \times$ $\left.10^{9} / 1\right)$. No microorganisms were found on microscopic and cultural examination. The diagnosis of chylothorax was thus established. Feedings was changed to Pregestamyl (fat as medium-chain triglycerides), but as there was no reduction in the drainage of chyle oral feeding was stopped, and intravenous hyperalimentation started on the thirteenth day $(160 \mathrm{ml} / \mathrm{kg}$ body weight in $24 \mathrm{~h})$. 
The chyle volume fell from $180 \mathrm{ml}$ on the twelfth day to $52 \mathrm{ml}$ on the sixteenth day and then stopped. As expected the serum protein level gradually increased, and returned to its previous level nine days after starting hyperalimentation. The left chest tube was removed on the eighteenth day, and formula feedings begun without reaccumulation of pleural fluid. The child's weight on the twenty-first day was $2900 \mathrm{~g}$.

\section{Discussion}

Postoperative chylothorax is a rare complication of thoracic and cardiovascular surgery, especially that involving the great vessels. ${ }^{1}$ Only one case of chylothorax complicating repair of diaphragmatic hernia (Bochdalek type) has been reported. ${ }^{2}$ The treatment of chylothorax is controversial. ${ }^{3}$ Continuous drainage with suction of the pleuralcavity has been advocated by Decancq. ${ }^{4}$ The use of dietary manipulation such as treatment with mediumchain tryglycerides was proposed by Hashin and Roy, ${ }^{56}$ since the volume and fat content of chyle is considerably altered by the diet. Surgical treatment is reserved for those cases where conservative treatment for one to two weeks has failed. Surgical treatment has often been unrewarding, since the leakage site is elusive, and when found, it is usually multiple. ${ }^{6}$

Our case was treated by parenteral hyperalimentation, combined with cessation of oral feedings and continuous pleural drainage. This treatment decreased the enteric lymph production, maintained a positive nitrogen balance, and prevented the need for surgical intervention.

\section{References}

${ }^{1}$ Kaul TK, Bain WH, Turner MA. Chylothorax: report of a case complicating ductus ligation through a median sternotomy, and review. Thorax 1976;31:610-6.

2 Weiner ES, Owens L, Salzberg AM. Chylothorax after Bochdalek herniorrhaphy in a neonate. $J$ Thorac Cardiovasc Surg 1973;65:200-5.

${ }^{3}$ Bessone LN, Ferguson TB, Burford TH. Chylothoraxcollective review. Ann Thorac Surg 1971;12:527-50.

${ }^{4}$ Decancq GH Jr. The treatment of chylothorax in children. Surg Gynecol Obstet 1965;121:509-12.

${ }^{5}$ Hashin SA, Roholt HB, Babayan VK et al. Treatment of chyluria and chylothorax with medium-chain tryglicerides. N Engl J Med 1964;270:756-64.

${ }^{6}$ Roy PH, Carr DT, Payne WS. The problem of chylothorax. Mayo Clin Proc 1976;42:457-67. 